\title{
TRANSSEXUALIDADE E DIGNIDADE DA PESSOA HUMANA
}

\section{TRANSSEXUALITY AND HUMAN DIGNITY}

\begin{abstract}
EDWIRGES ELAINE RODRIGUES
Mestranda em Direito, FCHS/UNESP; graduada em Direito, Faculdade de Direito de Franca; especialista em Direito Processual Civil, FCHS/UNESP; membro participante, PROEX; membro do NUPAD, UNESP; membro de grupo de pesquisa, CNPq; membro do IBDFAM. edwirges_elaine@yahoo.com.br
\end{abstract}

Maria Amália de Figueiredo Pereira Alvarenga

Doutora e mestre em Direito, UNESP; chefe do departamento de Direito Privado da UNESP; ex-coordenadora do curso de graduação em Direito da UNESP; docente da cadeira de Direito Civil da UNESP; docente do programa de pós graduação em Direito da UNESP; docente coordenadora, PROEX; orientadora de grupos de pesquisa, CNPq e

avaliadora de cursos pelo MEC. draamaliaalvarenga@yahoo.com.br

\section{RESUMO}

Este artigo resume-se a uma investigação sobre a transsexualidade ou disforia de gênero, em que o indivíduo não se identifica com o sexo que the foi imposto, mas sim, com o gênero oposto ao seu. Os indivíduos transexuais enfrentam inúmeros preconceitos e dificuldades ao longo de suas vidas, podendo-se afirmar que para alcançar sua completude, o transexual necessita reconhecer-se como titular do sexo oposto em todos os sentidos, médico (adequação do sexo biológico ao sexo psicológico), social (inclusão social deste indivíduo, para que seja aceito pela sociedade) e jurídico (perante a lei). No Brasil, não existe legislação específica a respeito da transsexualidade, assim, a regulamentação da cirurgia de transgenitalização é responsabilidade do Conselho Federal de Medicina, e após o árduo procedimento de transgenitalização, o transexual poderá obter a retificação do seu nome e sexo no registro civil, através de requerimento judicial. De maneira inovadora, alguns Tribunais, de acordo com o princípio da dignidade humana, têm concedido tais modificações antes mesmo da cirurgia de redesignação sexual, entretanto, este entendimento não está pacificado, o que acarreta grande injustiça e sofrimento a estas pessoas. Assim, busca-se demonstrar de maneira cristalina, a necessidade de legislação específica, a fim de facilitar o acesso dos transexuais, tanto à cirurgia de transgenitalização, quanto às retificações de nome e sexo no assento civil.

Palavras-chave: transsexualidade; dignidade da pessoa humana; cirurgia de transgenitalização; retificação do registro civil.

\begin{abstract}
This article summarizes an investigation about transsexuality or gender dysphoria, in which the individual does not identify with the sex that was imposed, but with the opposite gender to her/him. Transsexuals individuals face many prejudices and difficulties throughout their lives, can be said that to achieve its completeness, transsexuals need to be recognized as holder of the opposite sex in every way, medical (adequacy of biological sex to the psychological sex) , social (social inclusion of this individual, to be accepted by society) and legal (under the law). In Brazil, there is no specific legislation regarding transsexuality thus the regulation of reassignment surgery is the responsibility of the Federal Council of Medicine, and after hard reassignment procedure, the transsexual may obtain rectification of his name and sex in the civil registry through judicial application. Innovatively, some courts, in accordance with the principle of human dignity, have granted such changes even before the sex reassignment surgery, however, this understanding is not pacified, which causes great injustice and suffering to these people. Thus, it seeks to demonstrate clear way, the need for specific legislation in order to facilitate the access of transsexuals, both the reassignment surgery, as the rectification of name and sex in the civil registry.
\end{abstract}

Keywords: transsexuality; human dignity; sex reassignment surgery; rectification of civil registration. 


\section{SUMÁRIO}

INTRODUÇAO; 1 DIREITOS FUNDAMENTAIS; 1.1 Princípio da dignidade humana; 2 IDENTIDADE DE GÊNERO; 3 DIVERSIDADE SEXUAL; 4 TRANSSEXUALIDADE; 4.1 Teorias sobre as causas da transsexualidade; 5 CIRURGIA DE REDESIGNAÇÃO SEXUAL; 6 MODIFICAÇÃO DO NOME E SEXO EM REGISTRO CIVIL; 6.1 Retificação do Registro Civil sem cirurgia; CONCLUSÃO; REFERÊNCIAS.

\section{INTRODUÇÃO}

Cuida-se de pesquisa bibliográfica, utilizando-se o método dedutivo, no qual aplicam-se as leis ou regras gerais aos fatos particulares. Bem como, realiza-se uma análise qualitativa e quantitativa da jurisprudência pátria sobre a temática em questão.

No tocante à delimitação do tema-objeto deste artigo, buscou-se uma abordagem do indivíduo transexual e seus direitos fundamentais ditados pelo princípio da dignidade da pessoa humana, consagrado expressamente em nossa Lei Fundamental, art. $1^{\circ}$, III, e tido por ela como um valor essencial.

É considerada transexual a pessoa que não se identifica com o sexo que the foi imposto (biológico), mas sim, com o gênero oposto ao seu sexo; por ser o seu sexo biológico distinto do seu sexo psicológico. Neste sentido, esta pessoa pertence morfologicamente a um determinado sexo, mas psicologicamente pertence ao sexo contrário. Embora a transexualidade seja estudo de diversas áreas do conhecimento, ainda não se chegou a uma explicação científica que dê respostas exatas para a rejeição do próprio sexo e identificação com o gênero adverso.

No curso deste trabalho, ressalta-se as diversas batalhas enfrentadas pelo indivíduo transexual, desde a sua aceitação pela sociedade, passando pela submissão à cirurgia de readequação sexual, até a retificação do seu registro público, com a modificação do nome e sexo em seus documentos. Sendo que, as dificuldades são ainda maiores pela falta de legislação específica que abrace os transexuais, cabendo apenas ao Conselho Federal de Medicina ditar as regras de identificação da disforia de gênero e sua consequente correção, através de intervenção cirúrgica.

Convém, ainda, salientar que o Direito tem-se mostrado flexível acompanhando as mudanças sociais e, neste sentido, com fundamentos no princípio da dignidade da pessoa humana, alguns Tribunais se destacaram na vida dos transexuais ao permitir a modificação do 
nome e do sexo, mesmo sem a realização da cirurgia de readequação sexual. No entanto, tais decisões de vanguarda ainda são consideradas minoria, o que acarreta sofrimento e sensação de injustiça a estes indivíduos que, apenas buscam sua completude para então, alcançarem sua felicidade.

Desta maneira, faz-se imprescindível a criação de mecanismos legislativos que amparem o indivíduo transexual em todas as fases de sua vida, ou seja, no processo de hormonização, na cirurgia de transgenitalização, e em especial, na modificação do nome e sexo no registro civil, seja este procedimento anterior ou posterior à cirurgia.

\section{DIREITOS FUNDAMENTAIS}

Os direitos fundamentais representam o conjunto mínimo necessário para assegurar uma vida ao ser humano, baseado na liberdade e na dignidade para evitar que passe por sofrimentos.

Segundo Ingo Sarlet, os direitos fundamentais podem ser diferenciados dos direitos humanos, ao passo que o termo "direitos fundamentais" se aplica aqueles direitos do homem reconhecidos e positivados na esfera do direito Constitucional positivo de determinado Estado, enquanto a expressão "direitos humanos" faz referência aos direitos inerentes ao ser humano em nível supranacional, independentemente de sua vinculação à determinada ordem constitucional, aspirando validade universal. ${ }^{1}$

Os direitos fundamentais surgiram em meio a necessidade de limitação e controle dos abusos de poder do próprio Estado e de suas autoridades constituídas, consagrando, assim, os princípios básicos da igualdade e da legalidade como regentes do Estado moderno contemporâneo. Portanto, os direitos fundamentais colocam-se como uma das previsões necessárias a todas as Constituições, no sentido de valorizar o respeito à dignidade da pessoa humana, garantir limitação de poder e visar o pleno desenvolvimento da personalidade humana.

$\mathrm{Na}$ história constitucional brasileira, nunca uma carta política proclamou de maneira tão abrangente e pormenorizada os direitos e garantias fundamentais do homem, como o fez a Constituição Federal de 1988. Isto se dá pelo fato de ser o Brasil um Estado Democrático de Direito, art. $1^{\circ}$ da Constituição Federal, indispensável à concretização dos direitos fundamentais.

\footnotetext{
${ }^{1}$ SARLET, Ingo Wolfgang. A eficácia dos direitos fundamentais. $3^{\mathrm{a}}$ ed. rev. atual e ampl. Porto Alegre: Livraria do Advogado, 2003, pp. 33, 34. 
Pode-se afirmar que os direitos fundamentais são, em verdade, concretizações do máxi princípio fundamental da dignidade da pessoa humana, consagrado expressamente em nossa Lei Fundamental e tido por ela como um valor essencial.

\subsection{Princípio da dignidade humana}

A importância que se deu à pessoa variou no tempo e no espaço, o que revela um componente cultural na compreensão do que hoje se entende por dignidade humana. Assim, cumpre traçar a evolução histórico-filosófica do princípio da dignidade humana.

No pensamento filosófico e político da antiguidade clássica, a dignidade da pessoa humana era concedida, em regra, com base na condição social ocupada pelo indivíduo e o seu grau de reconhecimento pela sociedade. Desta forma, existiam pessoas mais dignas ou menos dignas, como, por exemplo,os escravos, que estavam reduzidos à servidão e não eram considerados merecedores de dignidade. Esta é a fase em que a dignidade era considerada relativa ${ }^{2}$.

Com o passar do tempo, o conceito de dignidade humana evoluiu. Na Idade Média, Tomás de Aquino foi o grande pensador a dedicar-se ao estudo do tema, o qual chegou a referirse expressamente ao termo "dignitas humana". O pensador defendia que a dignidade é uma virtude oferecida por Deus, sendo todo homem filho de Deus, portanto digno. ${ }^{3}$

No início da Idade Moderna, o humanista italiano Pico della Mirandola foi pioneiro ao desenvolver o princípio da dignidade, dando-lhe sentido fora da teologia. Ao justificar a idéia a grandeza e superioridade do homem em relação aos demais seres, afirmou que por ser criatura de Deus, ao homem foi outorgada uma natureza indefinida para que fosse seu próprio arbítrio, soberano e artífice, dotado da capacidade de ser e obter aquilo que ele próprio deseja. ${ }^{4}$

2 SARLET, Ingo Wolfgang. Dignidade da pessoa humana e direitos fundamentais na Constituição de 1988. Porto Alegre: Livraria do Advogado, 2001, p. 30.

${ }^{3}$ SARLET, Ingo Wolfgang, op.cit. p. 31.

${ }^{4}$ SARLET, Ingo Wolfgang, op.cit. p.107. 
Nesta mesma época, o espanhol Francisco de Vitória defendeu a existência de dignidade em todos os seres humanos, de onde se podia depreender que a escravidão era um crime, diferentemente do que se pensava na época. ${ }^{5}$

No âmbito do pensamento jusnaturalista dos séculos XVII e XVIII, o significado de dignidade enfrentou um processo de racionalização e laicização, predominando inalterada. No entanto, a noção fundamental da igualdade de todos os homens em dignidade e liberdade, destacando-se o pensador alemão Samuel Dufendorf, que defendia que todos deveriam respeitar a dignidade humana. Conforme Dufendorf, mesmo o monarca deveria admitir que seus súditos mais humildes eram detentores do direito de agir conforme a sua própria razão e entendimento. ${ }^{6}$

É com Kant, no século XVIII, que se secularizou a dignidade, que de uma vez por todas abandonou suas vestes sacrais. Para Kant, o ser humano não pode ser tratado como objeto nem por si próprio. ${ }^{7}$ Neste sentido, propôs a teoria do imperativismo categórico que prega que o homem é um fim em si mesmo, e por isso não pode ser tratado como objeto nem usado como meio de obtenção de qualquer objetivo. ${ }^{8}$

É justamente no pensamento de Kant que a doutrina mais expressiva parece identificar as bases de uma fundamentação e conceituação da dignidade da pessoa humana.

No século XX, a Segunda Guerra Mundial foi o cenário para que a dignidade humana tomasse novos rumos à sua constitucionalização, haja vista tamanhas atrocidades ocorridas naquela época, o mundo padecia sob os horrores do nazismo e fascismo, onde a dignidade voltou a ser relativa. Milhões de judeus, ciganos e homossexuais foram reunidos forçosamente em campos de concentração, sem qualquer dignidade.

Assim, a Segunda Guerra Mundial significou a ruptura com os direitos humanos. Logo, o pós-guerra deveria significar a sua reconstrução. Neste sentido, em 1945, 51 países assinaram a carta de fundação da ONU, e em 1948, foi aprovada a Declaração Universal dos Direitos Humanos, que faz referência à dignidade humana em seu art. $1^{\circ}$, "todos os seres humanos

\footnotetext{
${ }^{5}$ SARLET, Ingo Wolfgang, op.cit. p. 107.

${ }^{6}$ SARLET, Ingo Wolfgang, op.cit. p. 32.

7 SARLET, Ingo Wolfgang. Dignidade da pessoa humana e direitos fundamentais na Constituição de 1988. Porto Alegre: Livraria do Advogado, 2010, p.37.

${ }^{8}$ KANT, Immanuel. Fundamentação da metafísica dos costumes. Tradução Leopoldo Holzbach. São Paulo: Martin Claret, 2003, p. 69.
} 
nascem livres e iguais em dignidade e em direitos. Dotados de razão e de consciência, devem agir uns para com os outros em espírito e fraternidade". 9

A partir deste momento,começa a se desenvolver o Direito Internacional dos Direitos Humanos mediante a adoção de inúmeros tratados internacionais voltados à proteção dos direitos fundamentais. No âmbito do Direito Constitucional ocidental, percebe-se a elaboração de textos constitucionais abertos a princípios dotados de elevada carga axiológica, com destaque ao valor da dignidade humana.

No Brasil, a Constituição Federal de 1988 é o marco jurídico da transição democrática e da institucionalização dos direitos e garantias fundamentais. 0 texto demarca a ruptura com o regime autoritário militar instalado em 1964, refletindo o consenso democrático "pós-ditadura". É em seu art. $1^{\circ}$, que a CF reconhece a dignidade da pessoa humana como princípio basilar do direito pátrio.

Embora muitos não se atrevam a dizer o que é dignidade humana, Ingo Sarlet a conceitua como:

Qualidade intrínseca e distintiva reconhecida em cada ser humano que o faz merecedor do mesmo respeito e consideração por parte do Estado e da comunidade, implicando neste sentido, um complexo de direitos e deveres fundamentais que assegurem à pessoa tanto contra todo e qualquer ato de cunho degradante e desumano, como venham a the garantir as condições existenciais mínimas para uma vida saudável, além de propiciar e promover sua participação ativa e corresponsável nos destinos da própria existência e da vida em comunhão com demais elementos humanos. ${ }^{10}$

A dignidade da pessoa humana consagra-se assim, como verdadeiro princípio a orientar o Direito brasileiro, pois, nenhum princípio é mais valioso para compreender a unidade material da Constituição que o princípio da dignidade humana. Desta forma, apresentadas as razões, será com base neste máxi princípio que serão abordados e defendidos os direitos fundamentais da pessoa transexual.

\footnotetext{
9 ONU. Declaração universal dos direitos do homem. Disponível em: <http://www.humanrights.com/pt/what-are-human-rights/universal-declaration-of-humanrights/articles-01-10.html>. Acesso em: $1^{\circ}$ de Jul. 2014.

${ }^{10}$ SARLET, Ingo Wolfgang, op.cit. p. 60.
} 


\section{政

\section{IDENTIDADE DE GÊNERO}

Antes de adentrar ao tema da transexualidade, cumpre trabalhar os conceitos de gênero, sexo e identidade de gênero.

O termo "sexo" compreende diversos significados, cabendo sua utilização em diferentes sentidos, como, por exemplo, o conjunto de características anatômicas, segundo as quais um ser pode ser classificado como macho ou fêmea ou os próprios órgãos sexuais.

O dicionário Novo Aurélio define sexo como a "Conformação particular que distingue o macho da fêmea, nos animais e nos vegetais, atribuindo-lhes um papel determinado na geração e conferindo-lhes certas características distintivas"11.

Com o surgimento do conceito de gênero, a palavra "sexo" passou a ser utilizada num contexto mais ligado à biologia, como uma condição prescrita biologicamente ao indivíduo.

O termo "gênero", por sua vez, normalmente é utilizado numa acepção cultural e social, buscando afastar um determinismo biológico. De acordo com o dicionário Novo Aurélio, gênero significa também: "A forma culturalmente elaborada que a diferença sexual toma em cada sociedade, e que se manifesta nos papéis e status atribuídos a cada sexo e constitutivos da identidade sexual dos indivíduos."12

Mencionadas as definições de gênero e sexo, passa-se ao conceito de identidade de gênero.

Sabe-se que, biologicamente, há uma dualidade de sexos: feminino e masculino, sendo estes determinados pela genitália externa do indivíduo.

Assim, o indivíduo que possui o órgão sexual masculino (pênis) é biológica e socialmente considerado do gênero masculino. Já o indivíduo que detém o órgão sexual feminino (vagina) é biológica e socialmente considerado do gênero feminino.

É este sexo morfológico que será utilizado para a elaboração do registro civil de nascimento, que por lei deve constar o sexo do indivíduo.

Durante o desenvolvimento da personalidade do indivíduo, este, a partir dos componentes que concorrem para a formação de seu sexo, identifica-se com um determinado

\footnotetext{
${ }^{11}$ FERREIRA, Aurélio Buarque de Holanda. Novo Aurélio Século XXI: o dicionário da língua portuguesa. Rio de Janeiro: Nova Fronteira, 1999, p. 1849.

${ }^{12}$ FERREIRA, Aurélio Buarque de Holanda, op.cit. p. 980.
} 
gênero: feminino ou masculino, desenvolvendo uma convicção inafastável acerca de sua sexualidade.

A identidade de gênero se manifesta, portanto, como um sentimento do indivíduo quanto à sua identificação como homem ou mulher, o que pode ou não corresponder ao sexo atribuído a partir de seu nascimento.

É considerado Transtorno de Identidade de Gênero quando o indivíduo, seja ele homem ou mulher, não se identifica com o seu gênero, por ser o seu sexo biológico distinto do seu sexo psicológico. Assim, esta pessoa pertence morfologicamente a um determinado sexo, mas psicologicamente pertence ao sexo oposto.

As pessoas que possuem este transtorno de identidade de gênero são consideradas transexuais, pois o seu sexo psicossocial transcende ao sexo biológico.

\section{DIVERSIDADE SEXUAL}

É importante mencionar que identidade de gênero não se confunde com orientação sexual, pois a primeira, conforme visto no título anterior, é a forma como o indivíduo se identifica, seja pertencente ao gênero feminino ou masculino. Já orientação sexual diz respeito às formas pelas quais o indivíduo irá relacionar-se sexualmente.

Desde o início da humanidade, criou-se o costume de que o homem deve envolver-se amorosamente e sexualmente com uma pessoa do sexo oposto ao seu, ou seja, o sexo masculino deve-se relacionar com o sexo feminino e vice-versa.

Assim, heterossexuais são considerados os indivíduos que se sentem atraídos e se relacionam com pessoas do sexo oposto ao seu. Entretanto, desde a antiguidade, há relatos de pessoas que se comportavam de forma distinta a este costume. Deste modo, alguns homens preferiam relacionar-se com outros homens e mulheres se relacionavam com outras mulheres.

A estes grupos que sentem atração física e se relacionam com pessoas do mesmo sexo é dado o nome de homossexuais.

Com o passar do tempo, esta diversidade sexual ganhou força, e hoje, apesar de ainda enfrentar um enorme preconceito por parte da sociedade, não se limita apenas aos heterossexuais e homossexuais. 
Existem outros grupos como, por exemplo, os bissexuais que são pessoas que têm afinidade por indivíduos de ambos os sexos, ou seja, momentos se relacionam com pessoas do mesmo sexo e em outros instantes se relacionam com pessoas do sexo oposto.

Por sua vez, o grupo composto pelos travestis são, em sua maioria, homens que se vestem e se comportam conforme o sexo oposto ao seu, entretanto, sua orientação sexual é homossexual.

Também há de se mencionar que os travestis não se confundem com os transexuais, pois estes, ao contrário daqueles, têm aversão ao próprio órgão sexual, que não é considerado fonte de prazer $^{13}$. Frisando que a pessoa transexual, em regra, tem sua orientação sexual heterossexual, levando em consideração o seu sexo psicossocial.

Assexuada é considerada a pessoa que é desprovida de desejo sexual, não se sente atraída fisicamente por qualquer pessoa, seja do sexo feminino ou masculino. No entanto, uma pessoa que se diz assexuada pode apaixonar-se por outra, amá-la e ser feliz, ainda que nunca se sinta sexualmente atraída e não tenha necessidades sexuais.

Embora os grupos mencionados neste título representem a maior parte dos que compõem a diversidade sexual, deve-se ressaltar a existência de outros grupos, mas devido à complexidade que envolve a matéria, eles não serão, porém, abordados neste trabalho.

\section{TRANSSEXUALIDADE}

Transexual é considerado o indivíduo anatomicamente de um sexo, porém, que acredita veemente pertencer a outro sexo. Esta crença é tão forte que o transexual possui um desejo incessante de ter o corpo modificado com a finalidade de ajustar-se ao verdadeiro sexo, ou seja, ao seu sexo psicossocial.

Considera-se transexual feminino o indivíduo que nasceu com o órgão genital masculino, enquanto com o sexo psicossocial feminino, por sua vez, é considerado transexual masculino a pessoa que nasceu com a genitália feminina e possui psicologicamente o sexo masculino.

\footnotetext{
${ }^{13}$ NAVES, Bruno Torquato de Oliveira; SÁ, Maria de Fátima Freire de. Da autonomia na determinação do estado sexual. In: CORRÊA, Elídia Aparecida de Andrade. et al. (coords.). Biodireito e dignidade da pessoa humana. Curitiba: Juruá, 2006. p. 227.
} 
0 transexual é classificado como primário e secundário. Sendo considerado primário aquele indivíduo que manifesta desejo inequívoco de modificação do sexo, desde sua infância. Já o transexual secundário é aquele que encontra dificuldades para se identificar, podendo considerar-se homossexual ou travesti em alguns momentos de sua vida ${ }^{14}$.

Embora muitos defendam a despatologização da transexualidade e a inutilização da expressão transexualismo, a mesma ainda é classificada como transtorno de identidade de gênero, constante na lista de doenças mentais, (CID -10 Classificação Internacional de Doenças editada pela OMS).

Nesse sentido, a Resolução $n^{\circ} 1.955 / 10$ do Conselho Federal de Medicina, repetindo a previsão contida nas resoluções anteriores (de $n^{\circ} 1.482 / 97$ e $\left.n^{\circ} 1.652 / 02\right)$, estabelece os critérios mínimos para a definição do transexualismo:

Art. $3^{\circ}$ Que a definição de transexualismo obedecerá, no mínimo, aos critérios abaixo enumerados:

1. Desconforto com o sexo anatômico natural;

2. Desejo expresso de eliminar os genitais, perder as características primárias e secundárias do próprio sexo e ganhar as do sexo oposto;

3. Permanência desses distúrbios de forma contínua e consistente por, no mínimo, dois anos;

4. Ausência de outros transtornos mentais.

A resolução do Conselho Federal de Medicina descreve a pessoa transexual como portadora de "desvio psicológico permanente de identidade sexual, com rejeição do fenótipo e tendência à automutilação e/ou autoextermínio". ${ }^{15}$

Para Maria Helena Diniz, a transexualidade implica um drama jurídico-existencial, decorrente da cisão entre a identidade sexual física e a identidade psíquica, drama esse que transcende o incômodo psicológico e leva à efetiva rejeição do fenótipo, resultando em tendência à automutilação genital ou dos seios, ou ao autoextermínio. ${ }^{16}$

\footnotetext{
${ }^{14}$ NAVES, Bruno Torquato de Oliveira; SÁ, Maria de Fátima Freire de, op.cit. p. 228.

${ }^{15}$ CONSELHO FEDERAL DE MEDICINA. Resolução n. 1.955, de 12 de ag sto de 2010. Dispõe sobre a cirurgia de transgenitalismo e revoga a Resolução CFM n. 1.652/02. Diário Oficial da União, Brasília, DF, 03 set. 2010. Disponível em: <http://www.portalmedico.org.br/php/pesquisa_resolucoes.php\#>. Acesso em: $17 / 09 / 2011$.

${ }^{16}$ DINIZ, Maria Helena. 0 estado atual do biodireito. 6 ed. rev. aum. atual. São Paulo: Saraiva, 2009. p. 281.
} 


\subsection{Teorias sobre as causas da transsexualidade}

A transexualidade é estudada por diversas áreas do conhecimento, medicina, psicologia e ciências jurídicas. No entanto, a ciência ainda não identificou precisamente, do ponto de vista biológico, a explicação para a rejeição do gênero correspondente ao sexo.

Duas correntes se destacam neste assunto, a psicossexual e a neuroendócrina.

O psicanalista Stoller, defensor da teoria psicossexual, considera as influências ambientais em que a pessoa vive, fundamentando os desvios sexuais com base na análise da relação do transexual com sua mãe, na infância. ${ }^{17}$

Afirma Stoller que o tratamento deve ser iniciado nos primeiros anos de vida, através de terapia, para que haja tempo de corrigir os rumos da identidade de gênero. Passada esta fase, o tratamento estará comprometido. Neste sentido, Stoller defende a inexistência de cura para a transexualidade na fase adulta, restando a cirurgia de redesignação de sexo como única alternativa. $^{18}$

Já o endocrinologista Harry Benjamin, defensor da teoria neuroendócrina ou biossexual, explica a origem da transexualidade em virtude de alterações no hipotálamo (glândula que controla o comportamento sexual) que fazem com que a secreção androgênica produzida não atinja o centro de identidade sexual ou que não haja resposta a essa secreção, permanecendo o centro hipotalâmico com as características originais femininas.

A teoria neurológica, baseada em Benjamin e logo após formulada por holandeses, explica a transexualidade a partir do tamanho da região do cérebro em que desenvolvem os hormônios sexuais:

Estudando o hipotálamo de cadáveres, região do cérebro responsável pelo desenvolvimento dos hormônios sexuais, os cientistas descobriram que uma parte chama estria terminal é em média $44 \%$ maior nos homens do que nas mulheres. Ao medir a região em seis transexuais, os pesquisadores descobriram volumes até $52 \%$ menores do que a média masculina. Portanto, a região cerebral ligada à

17 CAMARGO, Mariana Carneiro Leão. A tutela jurídica da pessoa transexual. Monografia, 128 p., Universidade Federal do Paraná. Curitiba: 2011.2 Disponível em:<http://dspace.c3sl.ufpr.br/dspace/bitstream/handle/1884/31586/1514\%20MARINA\%20CARNEIRO\%20L EAO\%20DE\%20CAMARGO.pdf?sequence=1 >. Acesso em: 24 de junho de 2014, p. 26.

${ }_{18}$ GONÇALVES, Camila de Jesus Mello. A transexualidade sob a ótica dos direitos humanos: uma perspectiva de inclusão. Tese de Doutorado, 262 p., Faculdade de Direito da Universidade de São Paulo. São Paulo: 2012, p. 72. 
evolução da sexualidade seria, nos transexuais, mais próxima à das mulheres do que à dos homens. ${ }^{19}$

Simpatizante à teoria de Benjamin, o médico Roberto Farina, especialista no estudo sobre transexualidade, afirma que a criança já nasce transexual, com horror à sua genitália e jamais busca um companheiro homossexual, pois está identificada com o outro sexo desde a infância, o que, no entanto, se aplica apenas ao transexual primário. ${ }^{20}$

No entanto, entende-se que os fatores que levam um transexual a ser classificado como secundário não fazem dele menos transexual que o primário, pois muitas vezes a pessoa procura comportar-se de acordo com os padrões que a sociedade exige, na tentativa de superar seus anseios e preferências, ainda mais sabendo de todas as dificuldades que enfrentará em uma sociedade preconceituosa.

O fato de o transexual repudiar seus órgãos sexuais a ponto de querer extirpá-los não deve ser visto como a única forma de identificação da transsexualidade, pois estas características aparecerão com maior ou menor intensidade em cada indivíduo.

Assim, é possível que uma pessoa transexual consiga ter uma vida digna sem se submeter à cirurgia, que é altamente invasiva.

Ao contrário da suposição acima colocada, porém, muitos transexuais só encontrarão sua dignidade após a realização da cirurgia, que adequará seu sexo psicológico ao sexo biológico.

\section{CIRURGIA DA REDESIGNAÇÃO SEXUAL}

Vale ressaltar que a cirurgia para a modificação da genitália não é condição para o diagnóstico da transsexualidade, mas sim a última forma de tratamento, quando as demais forem inválidas.

Neste sentido, seguem as palavras de Elimar Szaniawski:

O fato de estar a pessoa perfeita e corretamente caracterizada como transexual não significa que a mesma deva, obrigatoriamente, ser submetida à cirurgia de

19 GONÇALVES, Camila de Jesus Mello. A transsexualidade sob a ótica dos direitos humanos: uma perspectiva de inclusão. Tese de Doutorado, 262 p., Faculdade de Direito da Universidade de São Paulo. São Paulo: 2012. p. 73. Apud: WEIS, Bruno. No corpo certo. Revista IstoÉ. São Paulo: 29. jun. 1998.

${ }^{20}$ GONÇALVES, Camila de Jesus Mello, op.cit. p. 72. 
mudança de sexo, que, segundo nosso entender, é de último e derradeiro recurso, utilizado somente depois da falência das demais terapias adequadas ao caso. $^{21}$

Assim, existem outras formas de tratamentos medicamentoso, hormonal, psicopedagógico e psiquiátrico que possibilitam que a pessoa viva como se pertencesse ao outro sexo, sem passar pela cirurgia. ${ }^{22}$

No entanto, esgotadas todas as possibilidades de tratamento não cirúrgico, a última alternativa é a redesignação sexual através de cirurgia.

Este procedimento cirúrgico de transgenitalização é bastante discutido no ordenamento jurídico brasileiro, pois, de um lado, poder-se-ia caracterizar esta cirurgia como mutilante, afastando a licitude de sua realização; por outro ângulo, justifica-se a legalidade de tal procedimento por se tratar da única forma de solucionar efetivamente o problema do transexual, tratando-se de uma cirurgia corretiva.

Entende-se como mais adequada a finalidade terapêutica da cirurgia,a qual afasta o caráter mutilador. Assim, torna-se admissível a disposição do direito à integridade física para autorizar a cirurgia de adequação sexual, na medida em que corresponde à realização do direito à saúde e à garantia da dignidade da pessoa humana, possibilitando o livre desenvolvimento da personalidade do indivíduo.

Sem uma legislação expressa que regulamente a situação do indivíduo transexual, o diagnóstico de transsexualidade e a possibilidade de intervenção cirúrgica, fica a cargo do Conselho Federal de Medicina que, em sua Resolução n 1.955 de 2010, dispõe a respeito:

Art. $4^{\circ}$ - Que a seleção dos pacientes para cirurgia de transgenitalismo obedecerá a avaliação de equipe multidisciplinar constituída por médico psiquiatra, cirurgião, endocrinologista, psicólogo e assistente social, obedecendo os critérios a seguir definidos, após, no mínimo, dois anos de acompanhamento conjunto:

1) Diagnóstico médico de transgenitalismo;

2) Maior de 21 (vinte e um) anos;

3) Ausência de características físicas inapropriadas para a cirurgia.

${ }^{21}$ SZANIAWSKI, Elimar. Limites e possibilidades do direito de redesignação do estado sexual. São Paulo: RT, 1999, p. 68.

22 Ibid. 
Através da resolução acima mencionada, a cirurgia de transgenitalização do tipo neocolpovulvoplastia (extirpação do pênis e construção da vagina) e/ou procedimentos complementares sobre gônadas e caracteres sexuais secundários como tratamento dos casos de transexualismo, deixa de ser realizada a título experimental.

Além disso, foi permitido que todos os procedimentos de transgenitalização sejam realizados em hospitais públicos ou privados, inclusive as cirurgias experimentais de neofaloplastia (transformação da vagina em pênis), desde que o hospital atenda aos requisitos estabelecidos e seu corpo clínico seja composto pelos profissionais previstos na equipe citada no artigo $4^{\circ}$.

\section{MODIFICAÇÃO DO NOME E SEXO NO REGISTRO CIVIL}

Pode-se afirmar que, para alcançar sua completude, o transexual necessita reconhecerse como titular do sexo oposto em todos os sentidos, seja médico (adequação do sexo biológico ao sexo psicológico), social (inclusão social deste indivíduo, para que seja aceito pela sociedade) e jurídico (perante a lei).

Assim, após a cirurgia de redesignação sexual, o indivíduo transexual não está completo, pois de nada adianta estar com a genitália compatível com o seu sexo psicossocial, mas ainda constar em seu Registro Civil o nome e o sexo do seu nascimento, que não condiz com a sua real personalidade.

Neste momento, trava-se uma nova batalha, o pedido de retificação do nome e sexo no Registro Civil. A alteração destes dados é bastante discutida, e a jurisprudência encontra-se dividida entre a possibilidade de tais modificações e a negativa para estes procedimentos. tratam

Sem legislação específica que defenda os direitos dos indivíduos transexuais, resta uma análise dos diplomas que regem o Registro Civil, a fim de encontrar uma solução para a retificação dos dados do transexual. Há dois diplomas que versam sobre o Registro Civil, o Código Civil que aborda o direito ao nome como um dos direitos da personalidade, e a Lei de Registros Públicos (Lei $n^{\circ}$ 6.015, de 31.12.1973) que trata a respeito do nome e gênero sexual, que devem constar no assento de nascimento. 
ISSN 1981-3694

(DOI): $10.5902 / 1981369418583$

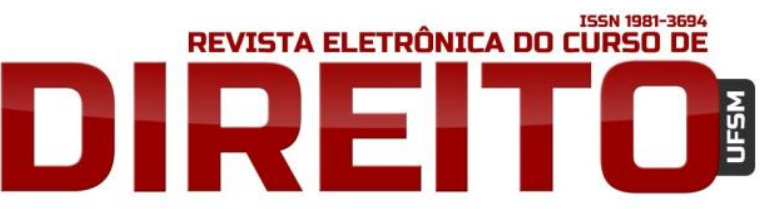

TRANSSEXUALIDADE E DIGNIDADE DA PESSOA HUMANA

EDWIRGES ELAINE RODRIGUES, Maria Amália de Figueiredo Pereira Alvarenga

Com relação a retificação registral, o Código Civil permite algumas alterações quanto ao sobrenome dos cônjuges (arts. $1.565, \$ 1^{\circ}$ e 1.578), sendo que ambos têm a faculdade de adotar o apelido de família do consorte. Já em caso de dissolução conjugal, o Código Civil permite aos consortes renunciar o sobrenome adotado, ou inclusive, mantê-lo após a separação/divórcio. Embora haja estas possibilidades de modificação do nome e sobrenome, quanto ao gênero sexual, o Código é silente.

A Lei de Registros Públicos também prevê situações pelas quais é possível a alteração, seja do prenome ou do sobrenome, entretanto, a alteração do prenome em decorrência de cirurgia de transgenitalização não está presente entre as alternativas. No entanto, muitos pedidos são aceitos, com base no art. 55, parágrafo único da lei, que permite a modificação de prenomes vergonhosos e ridículos. Pois, um indivíduo que se identifica como mulher realiza cirurgia de redesignação sexual e possui aparência feminina, certamente enfrenta momentos de humilhação ao apresentar documentos nos quais possui nome e sexo masculino, ou, vice e versa.

$\mathrm{Na}$ doutrina, identificam-se três grandes correntes a respeito do tema. A primeira delas detém uma visão conservadora, dentre os principais autores estão Luiz Flávio Borges D'Urso, Aracy Klabin e Matilde Josefina Sutter, que sustentam a impossibilidade jurídica de qualquer redesignação do gênero sexual no registro civil; a segunda corrente, com uma posição intermediária, é defendida por Rosa Maria de Andrade Nery, que admite a modificação, mas deve constar especificamente o termo transexual no assento de nascimento do requerente no lugar do gênero anterior; por sua vez, a terceira corrente, numa orientação liberal, os autores Antonio Chaves, Caio Mário da Silva Pereira, Luiz Alberto David Araújo, Elimar Szaniawski, Tereza Rodrigues Vieira e Ricardo Algarve Gregório defendem a possibilidade de substituição do gênero registral atual para o sexo oposto, sem qualquer averbação ou anotação no respectivo assento. ${ }^{23}$

Entende-se que a última corrente detém o posicionamento mais moderno e adequado, devendo ser aceita pelos Tribunais, em especial, com base no princípio da dignidade da pessoa humana que tem como principal fundamento evitar que a pessoa passe por humilhações e sofrimentos. Com este entendimento, segue julgado do TJMG:

23 GREGORIO, Ricardo Algarve. Transexualismo: identidade sexual e registral. In: MIGLIORE, Alfredo Domingues Barbosa. et al. (coordenadores). Dignidade da vida humana. São Paulo: LTr, 2010. pp. 219,220 . 
RETIFICAÇÃO DE REGISTRO DE NASCIMENTO - TRANSEXUAL - CIRURGIA DE TRANSGENITALIZAÇÃO JÁ REALIZADA - PRINCÍPIO DA DIGNIDADE DA PESSOA HUMANA - MUDANCA DE NOME - NECESSIDADE PARA EVITAR SITUACCÕES VEXATÓRIAS - INEXISTÊNCIA DE INTERESSE GENÉRICO DE UMA SOCIEDADE DEMOCRÁTICA À INTEGRAÇÃO DO TRANSEXUAL. - A força normativa da constituição deve ser vista como veículo para a concretização do princípio da dignidade da pessoa humana, que inclui o direito à mínima interferência estatal nas questões íntimas e que estão estritamente vinculadas e conectadas aos direitos da personalidade. - Na presente ação de retificação não se pode desprezar o fato de que o autor, transexual, já realizou cirurgia de transgenitalização para mudança de sexo e que a retificação de seu nome evitarlhe-á constrangimentos e situações vexatórias. - Não se deve negar ao portador de disforia do gênero, em evidente afronta ao texto da lei fundamental, o seu direito à adequação do sexo morfológico e psicológico e a consequente redesignação do estado sexual e do prenome no assento de seu nascimento. V.V. ${ }^{24}$

Assim, a adequação do prenome e do sexo redesignado do transexual, é medida que traduz proteção aos elementos fundamentais da personalidade do ser humano, quais sejam, a dignidade, a indivisibilidade e a pessoalidade. ${ }^{25}$

\subsection{Retificação do Registro Civil sem cirurgia}

Conforme visto no tópico anterior, mesmo sem legislação sobre o tema, após a realização da cirurgia de transgenitalização, é possível, mediante autorização judicial, modificar o nome e o sexo no Registro Civil de nascimento.

No entanto, entende-se que a cirurgia não deve ser requisito indispensável à autorização da modificação do assento civil. Pois, o princípio da dignidade da pessoa humana deve ser resguardado desde o início em que o indivíduo é identificado como pessoa transexual, não apenas quando há a readequação sexual após cirurgia.

Além disso, conforme a Resolução do CFM, a cirurgia apenas é realizada em transexuais com 21 anos ou mais, mas como fica a situação do indivíduo que se reconhece como transexual desde a infância ou adolescência? Este transexual também necessita ter seus direitos

\footnotetext{
${ }^{24}$ MINAS GERAIS. Tribunal de Justiça de Minas Gerais. MG 1.0024.05.778220-3/001(1), Relator: Edivaldo George dos Santos. Data de Julgamento: 06/03/2009. Data de Publicação: 07/04/2009.

${ }^{25}$ GREGORIO, Ricardo Algarve, op.cit. p. 221.
} 
fundamentais resguardados. Destarte, a modificação de nome e sexo no registro civil é a melhor forma de protegê-los!

Ademais, o indivíduo transexual, em decorrência de ter o sexo psíquico oposto ao seu sexo biológico, muitas vezes transforma seu corpo através de hormonioterapia e cirurgias plásticas, antes da cirurgia de readequação sexual, o que the acarreta grandes dissabores, pois, além de reconhecer-se como titular do sexo oposto, também the aparenta ser.

Sabe-se que o caminho para alcançar a cirurgia é longo e pode demorar anos. Durante todo este tempo de espera, a pessoa transexual também necessita de uma vida digna. Todavia, a dignidade fica cada vez mais distante, visto que o fato da pessoa ser visivelmente identificada como mulher e apresentar documentos com nome e sexo masculinos gera um profundo constrangimento e humilhação, fazendo com que se sinta menos digna que outras pessoas.

Em defesa ao princípio da dignidade humana, alguns Tribunais têm se destacado, ao permitir a retificação do nome e sexo no registro civil, antes do procedimento cirúrgico de transgenitalização. Neste sentido, segue o entendimento do E. Tribunal de Justiça de São Paulo:

\begin{abstract}
No caso, a requerente pretende a modificação de seu prenome e da designação sexual constante em seu Registro Civil, pois, tratando-se de transexual, vestindo-se, comportando-se e identificando-se como mulher perante a sociedade, sente-se constrangida ao apresentar documentos designando-a como pessoa do sexo masculino, de nome Antonio. 0 digno Magistrado sentenciante extinguiu o feito sem análise do mérito, ao fundamento de que inexiste interesse de agir quando ainda não realizada a cirurgia de redesignação de gênero. Não agiu, contudo, com o costumeiro acerto. A condição de transexual requer uma série de medidas de caráter multidisciplinar até que, finalmente, seja realizada a cirurgia que ajustará o sexo anatômico ao sexo psíquico. Durante este processo, em que o corpo já se adapta ao sexo psíquico, notório o constrangimento daquele que, aparentando um sexo, vê-se obrigado a mostrar documentos que sinalizam um outro. Exigir-se que se aguarde a realização da cirurgia é, com a devida vênia, atentar contra a dignidade da pessoa humana, prevista no artigo $1^{\circ}$, III, da Constituição Federal. Presente, portanto, o interesse de agir. De rigor, assim, a anulação da $r$. sentença para que a ação prossiga até o julgamento do mérito. ${ }^{26}$
\end{abstract}

Sabe-se que a cirurgia de transgenitalização é profundamente invasiva e dolorosa, sendo necessária a realização de vários procedimento cirúrgicos para obter o resultado desejado. No mais, existem transexuais que aceitam seus órgãos genitais, e não têm intenção

${ }^{26}$ SÃO PAULO. Tribunal de Justiça de São Paulo. Apelação 0007491-04.2013.8.26.0196. $4^{\text {a }}$ Câmara de Direito Privado. Relator Des. Maia da Cunha. Data da publicação: 13 de agosto de 2013. 
de modificá-los. De tal modo, não se pode forçar uma pessoa a se submeter a esta cirurgia para então alcançar a modificação do seu nome e sexo no registro civil.

Neste sentido, segue o brilhante julgado:

Registro civil. Alteração de prenome e sexo da requerente em virtude de sua condição de transexual. Admissibilidade. Hipótese em que provada, pela perícia multidisciplinar, a desconformidade entre o sexo biológico e o sexo psicológico da requerente. Registro civil que deve, nos casos em que presente prova definitiva do transexualismo, dar prevalência ao sexo psicológico, vez que determinante do comportamento social do indivíduo. Aspecto secundário, ademais, da conformação biológica sexual, que torna despicienda a prévia transgenitalização. Observação, contudo, quanto à forma das alterações que devem ser feitas mediante ato de averbação com menção à origem da retificação em sentença judicial. Ressalva que não só garante eventuais direitos de terceiros que mantiveram relacionamento com a requerente antes da mudança, mas também preserva a dignidade da autora, na medida em que os documentos usuais a isso não farão qualquer referência. Decisão de improcedência afastada. Recursos providos, com observação. ${ }^{27}$

Embora já existam decisões de vanguarda, como estas acima mencionadas, sabe-se que o caminho para alcançar os direitos fundamentais dos transexuais, ainda é distante. Por ainda não haver pacificação desta matéria, existe discordância dentro dos próprios Tribunais, que em determinados momentos consideram a cirurgia dispensável, mas em outros instantes não reconhecem os pedidos de retificação de sexo antes da cirurgia, concedendo apenas a modificação do nome.

Neste sentido segue a jurisprudência:

REGISTRO CIVIL. TRANSEXUALIDADE. PEDIDO DE ALTERAÇÃO DE PRENOME E DE SEXO. ALTERAÇÃO DO NOME. POSSIBILIDADE. AVERBAÇÃO À MARGEM. A ALTERAÇÃO DO SEXO SOMENTE SERÁ POSSÍVEL APÓS A CIRURGIA DE TRANSGENITALIZAÇÃO. 1. O fato da pessoa ser transexual e exteriorizar tal orientação no plano social, vivendo publicamente como mulher, sendo conhecido por apelido, que constitui prenome feminino, justifica a mudança do nome, já que o nome registral é compatível com o sexo masculino. 2. Diante das condições peculiares da pessoa, o seu nome de registro está em descompasso com a identidade social, sendo capaz de levar seu usuário a situação vexatória ou de ridículo, o que justifica plenamente a alteração. 3. Deve ser averbado que houve determinação judicial modificando o registro, sem menção à razão ou ao conteúdo das alterações procedidas, resguardando-se, assim, a publicidade dos registros e a intimidade do requerente. 4. No entanto, é descabida a alteração do registro civil para fazer constar dado não verdadeiro, isto é, que o autor seja

27 SÃO PAULO. Tribunal de Justiça de São Paulo. Apelação 0008539-56.2004. 6 6 Câmara de Direito Privado. Relator Des. Vito Guglielmi. Data do julgamento: 18.10.2012. 
do sexo feminino, quando inequivocamente ele é do sexo masculino, pois ostenta órgão genitais tipicamente masculinos. 5. A definição do sexo é ato médico e o registro civil de nascimento deve espelhar a verdade biológica, somente podendo ser corrigido quando se verifica erro. Recurso desprovido, por maioria. ${ }^{28}$

Por estes motivos, faz-se necessário um maior respaldo jurídico aos indivíduos transexuais, através da criação de legislação específica com a finalidade de ampará-los tanto no processo de transgenitalização, mas, em especial, nos atos de retificação do nome e do sexo no assento civil, independentemente de cirurgia.

Desta forma, resta concluir que o sexo do indivíduo não pode ser ditado apenas pela genitália que este porta, mas sim pela forma como ele se identifica. A identidade sexual, consoante Carlos Cury, "é a manifestação espontânea, seja no sentimento, ou na expressão de pertencer ao sexo feminino ou masculino independente dos seus cromossomos". ${ }^{29}$

\section{CONCLUSÃO}

A transexualidade é estudada por diversas áreas do conhecimento, medicina, psicologia e ciências jurídicas. No entanto, a ciência ainda não identificou precisamente, do ponto de vista biológico, a explicação para a rejeição do gênero correspondente ao sexo.

Há duas correntes que se destacam neste assunto, a psicossexual, liderada pelo psicanalista Stoller, e a neuroendócrina, defendida pelo endocrinologista Harry Benjamin. Embora tenham visões distintas sobre este assunto, ambos os cientistas defendem a cirurgia de redesignação sexual como última e única terapia possível.

No Brasil, não há legislação específica sobre o tema da transexualidade, cabendo ao Conselho Federal de Medicina estabelecer as regras para a realização da cirurgia. Após ser submetido cirurgicamente e ter seus órgãos sexuais modificados, o transexual deverá acionar o judiciário para ter seus documentos reajustados ao seu novo gênero, com alteração do nome e sexo.

${ }^{28}$ RIO GRANDE DO SUL.Tribunal de Justiça do Rio Grande do Sul - AC: 70064503675 RS , Relator: Sérgio Fernando de Vasconcellos Chaves, Data de Julgamento: 24/06/2015, Sétima Câmara Cível, Data de Publicação: Diário da Justiça do dia 06/07/2015.

${ }^{29}$ Cury, Carlos Abib. Transexualidade: da mitologia à cirurgia. São Paulo: Iglu Editora, 2012, p. 33. 
ISSN 1981-3694

(DOI): $10.5902 / 1981369418583$

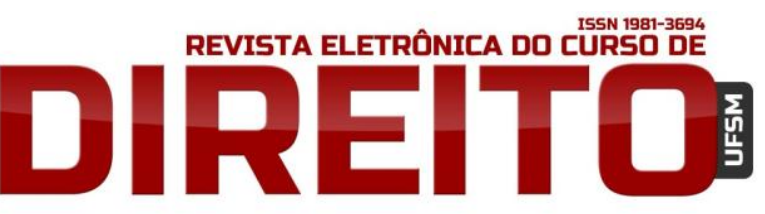

TRANSSEXUALIDADE E DIGNIDADE DA PESSOA HUMANA

EDWIRGES ELAINE RODRIGUES, Maria Amália de Figueiredo Pereira Alvarenga

Conquanto muitos doutrinadores defendam a impossibilidade de alterar o sexo biológico no registro civil, o posicionamento contrário a este já está pacificado jurisprudencialmente.

Entretanto, o fato de o transexual repudiar seus órgãos sexuais, a ponto de querer extirpá-los, não deve ser visto como a única forma de identificação da transexualidade, pois estas características aparecerão com maior ou menor intensidade em cada indivíduo. Assim, é possível que uma pessoa transexual se aceite sem se submeter à cirurgia, que é altamente invasiva.

Este transexual também necessita de ter seus direitos fundamentais resguardados. Destarte, a modificação de nome e sexo no registro civil é a melhor forma de protegê-los e lhes conceder uma vida digna!

Deste modo, deve-se concluir que a cirurgia de redesignação sexual não dever ser considerada requisito para a retificação do registro civil. Entretanto, faz-se necessária a criação de legislação especial, a fim de resguardar a dignidade dos transexuais tanto no processo de transgenitalização, quanto nos atos de retificação do nome e do sexo no assento civil, independentemente de cirurgia.

\section{REFERÊNCIAS}

CALANDRA, Henrique Nelson. Identidade sexual: visão médica e jurídica. In: MIGLIORE, Alfredo Domingues Barbosa. et al. (coordenadores). Dignidade da vida humana. São Paulo: LTr, 2010.

CAMARGO, Mariana Carneiro Leão. A tutela jurídica da pessoa transexual. Monografia, 128 p., Universidade Federal do Paraná. Curitiba: 2011. Disponível

em:<http://dspace.c3sl.ufpr.br/dspace/bitstream/handle/1884/31586/1514\%20MARINA\%20CARN EIRO\%20LEAO\%20DE\%20CAMARGO.pdf?sequence=1 >. Acesso em: 24 de junho de 2014.

CONSELHO FEDERAL DE MEDICINA. Resolução n. 1.955, de 12 de agosto de 2010. Dispõe sobre a cirurgia de transgenitalismo e revoga a Resolução CFM n. 1.652/02. Diário Oficial da União, Brasília, DF, 03 set. 2010. Disponível em:

<http://www.portalmedico.org.br/php/pesquisa_resolucoes.php\#>. Acesso em: 17/09/2011.

CURY, Carlos Abib. Transexualidade: da mitologia à cirurgia. São Paulo: Iglu Editora, 2012. 
DINIZ, Maria Helena. O estado atual do biodireito. 6 ed. rev. aum. atual. São Paulo: Saraiva, 2009.

FERREIRA, Aurélio Buarque de Holanda. Novo Aurélio Século XXI: o dicionário da língua portuguesa. Rio de Janeiro: Nova Fronteira, 1999.

GONÇALVES, Camila de Jesus Mello. A transexualidade sob a ótica dos direitos humanos: uma perspectiva de inclusão. Tese de Doutorado, 262 p., Faculdade de Direito da Universidade de São Paulo. São Paulo: 2012.

GREGORIO, Ricardo Algarve. Transexualismo: identidade sexual e registral. In: MIGLIORE, Alfredo Domingues Barbosa. et al. (coordenadores). Dignidade da vida humana. São Paulo: LTr, 2010.

KANT, Immanuel. Fundamentação da metafísica dos costumes. Tradução Leopoldo Holzbach. São Paulo: Martin Claret, 2003.

LUZ, Jamile Pereira. Implicações jurídicas do reconhecimento do direito à identidade sexual: uma análise da transexualidade. Revista Eletrônica do Curso de Direito UNIFACS. n. 151, jan. 2013. Disponível em: < http://www.revistas.unifacs.br/index.php/redu/article/view/2445>. Acesso em: 24 de junho de 2014.

MALUF, Adriana Caldas do Rego Freitas Dabus. A identidade de gênero à luz dos direitos da personalidade. In: MIGLIORE, Alfredo Domingues Barbosa. et al. (coords.). Dignidade da vida humana. São Paulo: LTr, 2010. p. 196-210.

MINAS GERAIS. Tribunal de Justiça de Minas Gerais. MG 1.0024.05.778220-3/001(1), Relator: Edivaldo George dos Santos. Data de Julgamento: 06/03/2009. Data de Publicação: 07/04/2009.

NAMBA, Edison Tetsuzo. Manual de bioética e biodireito. São Paulo: Atlas, 2009.

NAVES, Bruno Torquato de Oliveira; SÁ, Maria de Fátima Freire de. Da autonomia na determinação do estado sexual. In: CORRÊA, Elídia Aparecida de Andrade. et al. (coords.). Biodireito e dignidade da pessoa humana. Curitiba: Juruá, 2006.

ONU. Declaração universal dos direitos do homem. Disponível em: <http://www. humanrights.com/pt/what-are-human-rights/universal-declaration-of-humanrights/articles-01-10.html. . Acesso em: $1^{\circ}$ de Jul. 2014.

RIO GRANDE DO SUL.Tribunal de Justiça do Rio Grande do Sul - AC: 70064503675 RS , Relator: Sérgio Fernando de Vasconcellos Chaves, Data de Julgamento: 24/06/2015, Sétima Câmara Cível, Data de Publicação: Diário da Justiça do dia 06/07/2015. 
ISSN 1981-3694

(DOI): $10.5902 / 1981369418583$

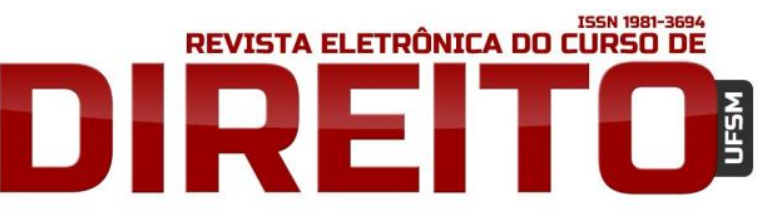

TRANSSEXUALIDADE E DIGNIDADE DA PESSOA HUMANA

EDWIRGES ELAINE RODRIGUES, MARIA AMÁlia de FIgUEIREDO PEREIRA ALVARENGA

SÃO PAULO. Tribunal de Justiça de São Paulo. Apelação 0007491-04.2013.8.26.0196. $4^{\text {a }}$ Câmara de Direito Privado. Relator Des. Maia da Cunha. Data da publicação: 13 de agosto de 2013.

SÃO PAULO. Tribunal de Justiça de São Paulo. Apelação 0008539-56.2004. $6^{\text {a }}$ Câmara de Direito Privado. Relator Des. Vito Guglielmi. Data do julgamento: 18.10.2012.

SARLET, Ingo Wolfgang. A eficácia dos direitos fundamentais. $3^{\text {a }}$ ed. rev. atual e ampl. Porto Alegre: Livraria do Advogado, 2003.

- Dignidade da pessoa humana e direitos fundamentais na Constituição de1988. Porto Alegre: Livraria do Advogado, 2001.

. Dignidade da pessoa humana e direitos fundamentais na Constituição de 1988. Porto Alegre: Livraria do Advogado, 2010.

SCRECCIA, Elio. Manual de bioética: fundamentos e ética biomédica. v.1. 3. ed. rev. atual. São Paulo: Edições Loyola, 2009.

SZANIAWSKI, Elimar. Limites e possibilidades do direito de redesignação do estado sexual. São Paulo: RT, 1999.

Recebido em: 26.06.2015/ Revisões em: 01.10.2015 / Aprovado em: 13.10.2015 